\title{
EKSPERIMENTASI MODEL PEMBELAJARAN KOOPERATIF TIPE JIGSAW DENGAN PENDEKATAN CTL TERHADAP PRESTASI BELAJAR DAN ASPEK AFEKTIF SISWA DITINJAU DARI KEMAMPUAN SPASIAL SISWA
}

\author{
Habib Ratu Perwira Negara ${ }^{1}$, Tri Atmojo $K^{2} \&$ Imam Sujadi ${ }^{3}$ \\ ${ }^{123}$ UNS Surakarta, Jawa Tengah, Indonesia \\ g4ra27@gmail.com
}

\begin{abstract}
Abstrak
Tujuan dari penelitian ini adalah untuk mengetahui perbedaan dampak antrara penerapan pembelajaran koperatif tipe Jigsaw dengan pendekatan pembelajaran kontekstual, penerapan pembelajaran koperatif tipe Jigsaw tanpa pendekatan pembelajaran kontekstual, dan pembelajaran langsung terhadap hasil belajar siswa dan aspek affektif siswa dengan memperhatikan kemampuan spasial siswa yang tergolong ke dalam katagori tinggi, sedang, dan rendah. Penelitian ini adalah quasi experimen. Hasil dari penelitian ini menunjukkan bahwa (1) Dalam hal prestasi belajar, kedua model pembelajaran kooperatif tipe Jigsaw baik dengan pendekatan CTL maupun yang tidak menghasilkan prestasi belajar yang lebih baik daripada model pembelajaran langsung. Selain itu, model pembelajaran kooperatif tipe Jigsaw dengan pendekatan CTL menghasilkan prestasi belajar yang sama baiknya dengan model pembelajaran kooperatif tipe Jigsaw tanpa CTL. (2) Sedangkan dalam perspektif affektif siswa, model pembelajaran kooperatif tipe Jigsaw dengan pendekatan CTL menghasilkan aspek afektif yang lebih baik jika dibandingkan dengan baik model pembelajaran kooperatif tipe Jigsaw maupun model pembelajaran langsung. Lebih lanjut lagi, model pembelajaran kooperatif tipe Jigsaw menghasilkan aspek afektif yang lebih baik daripada model pembelajaran langsung. (3) Siswa dengan kemampuan spasial tinggi dan sedang mempunyai prestasi belajar yang lebih baik daripada siswa dengan kemampuan spasial rendah, serta siswa dengan kemampuan spasial sedang mempunyai prestasi belajar yang lebih baik daripada siswa dengan kemampuan spasial rendah. (4) Siswa dengan kemampuan spasial tinggi mempunyai aspek afektif yang lebih baik daripada siswa dengan kemampuan spasial sedang dan rendah, serta aspek afektif siswa dengan kemampuan spasial sedang sama baiknya dengan siswa yang mempunyai kemampuan sapasial rendah. Hasil penelitian lainnya dari penelitian ini diuraikan pada bagian pembahasan dan kesimpulan artikel ini.
\end{abstract}

Keywords: Jigsaw, Pembelajaran Kontekstual, Kemampuan Spasial, Hasil Belajar, \& Afektif

\section{Abstract}

The current research intends to find out the different effect of the Jigsaw type of cooperative learning model with CTL approach, the Jigsaw type of cooperative learning model without CTL approach, and the direct learning model towards students mathematics learning achievement and affective aspect regarding student spatial ability which is categorized into high, medium and low. The research was quasi experimental. The results of the research were as follows. (1) The cooperative learning model of Jigsaw type with CTL approach and the cooperative learning model of Jigsaw type gaves a better achievement than direct learning model, and the cooperative learning model of Jigsaw type with CTL approach gaves the same achievement as the cooperative learning model of Jigsaw type. (2) The cooperative learning model of Jigsaw 
Perwiranegara, H., K, T., \& Sujadi, I. (2016). EKSPERIMENTASI MODEL PEMBELAJARAN KOOPERATIF TIPE JIGSAW DENGAN PENDEKATAN CTL TERHADAP PRESTASI BELAJAR DAN ASPEK AFEKTIF SISWA DITINJAU DARI $\begin{array}{lllll}\text { KEMAMPUAN } & \text { SPASIAL } & \text { SISWA. JURNAL } & \text { TATSQIF, } & 14(2) .\end{array}$ from http://ejurnal.iainmataram.ac.id/index.php/tatsqif/article/view/1008

type with CTL approach results a better affective effect than the cooperative learning model of Jigsaw type and direct learning model, and the cooperative learning model of Jigsaw type gaves a better achievement than direct learning model. (3) Students with the high spatial ability had better achievement than students with the medium and low spatial ability, and students with the medium spatial ability had better achievement than students with the low spatial ability. (4) Students with the high spatial ability had better affective aspect than students with the medium and low spatial ability, and students with the medium spatial ability had the same affective aspect as students with the the low spatial ability. More findings are elaborated further on the discussion and conclusion part of the current report.

Keywords: Jigsaw, CTL approach, spatial ability, learning achievement, and affective aspect.

\section{PENDAHULUAN}

Matematika secara garis besar dibagi menjadi empat cabang yaitu aritmetika, aljabar, geometri, dan analisis (Bell dalam Abdussakir \& Achadiyah, 2009: 388). Geometri merupakan cabang matematika yang menempati posisi penting untuk dipelajari karena geometri digunakan oleh setiap orang dalam kehidupan sehari-hari (Walle dalam Abdussakir dan Nur Laili Achadiyah, 2009: 388). Kurangnya siswa dalam memahami geometri, membuat siswa tidak dapat mengembangkan diri. Fakta-fakta yang menunjukkan rendahnya penguasaan geometri baik di Indonesia maupun di luar negeri dimana hasil yang ditunjukkan bahwa banyak siswa SLTP dan SLTA kurang memahami konsep-konsep geometri. Somerset (1996) melaporkan hasil tes diagnostik matematika yang dilaksanakan oleh Suryanto, bahwa rata-rata proporsi jawaban benar atau hampir benar yang dicapai oleh 482 siswa kelas 3 SLTP dari 16 sekolah hanya 29,0\%. Clements dan Battista (1992) menyatakan bahwa hasil evaluasi terhadap siswa-siswa sekolah menengah di Amerika Serikat, sebagai-mana dilaporkan oleh Fuys, et al (1988), menggambarkan bahwa mereka gagal dalam mempelajari konsep dasar geometri.

Hal ini juga dapat dilihat dari hasil PAMER UN 2013 terkait materi pokok yang diujikan pada Ujian Nasional di Kota Madiun Tahun Ajaran 2013. Adapun dari lima materi pokok, daya serap dimensi tiga menempati posisi 
Perwiranegara, H., K, T., \& Sujadi, I. (2016). EKSPERIMENTASI MODEL PEMBELAJARAN KOOPERATIF TIPE JIGSAW DENGAN PENDEKATAN CTL TERHADAP PRESTASI BELAJAR DAN ASPEK AFEKTIF SISWA DITINJAU DARI $\begin{array}{llllr}\text { KEMAMPUAN } & \text { SPASIAL } & \text { SISWA. JURNAL } & \text { TATSQIF, } & 14(2) .\end{array}$ from http://ejurnal.iainmataram.ac.id/index.php/tatsqif/article/view/1008

paling rendah, yaitu 52,49\%. Kurangnya siswa dalam mengerjakan bentuk pemecahan masalah dapat dilihat dari hasil Ujian Nasional 2013 pada submateri yang diujikan dalam materi dimensi tiga. Persentase daya serap dalam menyelesaikan masalah yang berkaitan dengan kerangka atau jaringjaring bangun ruang sebesar 59,26\%, volume bangun ruang sebesar 53,79\%, dan luas permukaan bangun ruang sebesar 45,02\%. Kemampuan yang diperoleh siswa pada Ujian Nasional di Kota Madiun ini sangat rendah bila dibandingkan dengan materi lain. Hasil ini menunjukkan bahwa hasil belajar geometri bangun ruang sisi datar di Kota Madiun membutuhkan penanganan dan perbaikan.

Penilaian pencapaian belajar siswa tidak hanya menyangkut aspekaspek kognitif saja, tetapi juga mengenai aspek afektif yang menyangkut sikap serta internalisasi nilai-nilai yang perlu ditanamkan dan dibina melalui pelajaran yang diberikan. Menurut Sudjana (2008: 22), ranah afektif berkenaan dengan sikap yang terdiri dari lima aspek, yakni penerimaan, jawaban atau reaksi, penilaian, organisasi dan internalisasi. Masalah yang ditemukan di lapangan bahwa masalah aspek afektif belum memperoleh perhatian seperti pada kedua aspek lainya. Ini sesuai dengan penelitian oleh Sari (2013), dimana dikemukakan bahwa aspek afektif pada pembelajaran matematika belum dianggap sebagai penilaian yang utama, dan lebih lanjut dinyatakan bahwa dalam mata pelajaran matematika, aspek afektif begitu menunjang dalam pembelajaran siswa setiap hari untuk proses balajar siswa. Pendapat ini juga sesuai dengan penelitian yang dilakukan Lim dan Chapman (2013) yang menyatakan bahwa pemberian prioritas pada domain afektif meningkatkan kinerja dalam matematika. Selanjutnya, hasil penelitian yang dilakukan oleh Sukanti (2011) menyimpulkan bahwa pengembangan ranah afektif di sekolah akan membawa pengaruh yang sangat positif dalam kehidupan siswa selanjutnya, baik di rumah maupun di masyarakat. Berdasarkan hasil penelitian yang diuraikan tersebut, dapat disimpulkan 
Perwiranegara, H., K, T., \& Sujadi, I. (2016). EKSPERIMENTASI MODEL PEMBELAJARAN KOOPERATIF TIPE JIGSAW DENGAN PENDEKATAN CTL TERHADAP PRESTASI BELAJAR DAN ASPEK AFEKTIF SISWA DITINJAU DARI $\begin{array}{llllr}\text { KEMAMPUAN SPASIAL } & \text { SISWA. JURNAL } & \text { TATSQIF, } & 14(2) .\end{array}$ from http://ejurnal.iainmataram.ac.id/index.php/tatsqif/article/view/1008

bahwa aspek afektif memberikan hasil yang terus menerus yang akan menjadi efek yang dapat digunakan dalam kehidupan siswa.

Perlunya memperhatikan prestasi belajar dan aspek afektif dalam proses belajar mengajar merupakan tujuan penilaian hasil belajar untuk mengetahui perbedaan kemampuan siswa dan mengukur keberhasilan mereka, baik individu maupun kelompok. Proses pembelajaran sangat menentukan dalam hal ini, untuk itu agar tujuan ini tercapai, perlunya pemilihan pendekatan dan model pengajaran yang sesuai. Jika melihat model pembelajaran saat ini, yaitu hanya berorientasi pada guru sehingga siswa kurang untuk memperoleh pengalaman langsung, sehingga aspek afektif siswa terlihat kurang dilatih. Proses pembelajaran yang berkualitas sangat diperlukan, yakni proses pembelajaran yang dapat membuat situasi yang kondusif, sehingga akan menumbuhkan minat siswa dalam belajar.

Menurut Komalasari (2010: 54), pendekatan pembelajaran dapat diartikan sebagai titik tolak atau sudut pandang kita terhadap proses pembelajaran, yang merujuk pada pandangan tentang terjadinya suatu proses yang sifatnya masih sangat umum, didalamnya mewadahi, menginspirasi, menguatkan, dan melatari metode pembelajaran dengan cakupan teoritis tertentu. Dengan kata lain, pendekatan pembelajaran merupakan bungkus atau bingkai dari penerapan suatu strategi pembelajaran, metode pembelajaran dan teknik pembelajaran. Berbagai pendekatan pembelajaran yang berkembang saat ini diantaranya adalah Contextual Teaching and Learning (CTL). CTL adalah pendekatan pembelajaran yang bertitik tolak dari hal-hal yang real bagi siswa, menekankan keterampilan process of doing mathematics, berdiskusi dan berkolaborasi, berargumentasi dengan teman sekelas sehingga mereka dapat menemukan sendiri (student inventing sebagai kebalikan dari teacher telling) dan pada akhirnya menggunakan matematika itu untuk menyelesaikan masalah baik secara individu maupun kelompok. 
Perwiranegara, H., K, T., \& Sujadi, I. (2016). EKSPERIMENTASI MODEL PEMBELAJARAN KOOPERATIF TIPE JIGSAW DENGAN PENDEKATAN CTL TERHADAP PRESTASI BELAJAR DAN ASPEK AFEKTIF SISWA DITINJAU DARI $\begin{array}{llllr}\text { KEMAMPUAN SPASIAL } & \text { SISWA. JURNAL } & \text { TATSQIF, } & 14(2) .\end{array}$ from http://ejurnal.iainmataram.ac.id/index.php/tatsqif/article/view/1008

Pendekatan pembelajaran matematika yang digunakan selama ini, siswa hanya difokuskan menyelesaikan soal, akibatnya siswa kurang menghayati atau memahami konsep-konsep matematika, dan siswa mengalami kesulitan untuk mengaplikasikan matematika dalam kehidupan sehari-hari. Hal ini sesuai dengan pendapat Sutama, et al (2013) yang menyatakan bahwa dominasi guru dalam mengajar membuat komunikasi pembelajaran matematika tidak efektif. Pembelajaran matematika matematika cenderung berorientasi pada buku teks dan tidak mengkaitkan dengan kehidupan sehari-hari, serta kurangnya guru melakukan pembelajaran yang berguna dengan menggunakan strategi yang menarik.

Pembelajaran matematika di kelas seharusnya ditekankan pada keterkaitan antara konsep-konsep matematika dengan pengalaman siswa sehari-hari. Hal ini sesuai dengan pendapat Westera (2011: 202) yang menyatakan dasar dari pembelajaran kontekstual atau pembelajaran berbasis konteks adalah bahwa belajar tidak dapat terjadi dalam ruang hampa, tapi harus dihubungkan dengan dunia nyata. CTL menuntun siswa untuk memperoleh pengetahuan yang bermakna, sehingga siswa merasa akrab dengan matematika dan menimbulkan minat serta motivasi dalam penguasaan materi. Hal yang sama diungkapkan oleh Berns dan Erickson (2001: 2) yang menyatakan CTL membantu siswa menghubungkan konten mereka belajar dengan konteks kehidupan. Siswa menemukan makna dalam proses pembelajaran. Saat mereka berusaha untuk mencapai tujuan pembelajaran, mereka memanfaatkan pengalaman mereka sebelumnya dan membangun pengetahuan yang sudah ada.

Model pembelajaran yang menempatkan siswa sebagai pusat belajar diantaranya adalah model cooperative learning. Zakaria dan Iksan (2007: 37) menyatakan bahwa penggunaan model pembelajaran kooperatif pada matematika dan ilmu sains sangat efektif. Adapun model pembelajaran kooperatif yang mungkin bisa digunakan untuk membelajarkan geometri diantaranya adalah model pembelajaran kooperatif tipe Jigsaw. Model 
Perwiranegara, H., K, T., \& Sujadi, I. (2016). EKSPERIMENTASI MODEL PEMBELAJARAN KOOPERATIF TIPE JIGSAW DENGAN PENDEKATAN CTL TERHADAP PRESTASI BELAJAR DAN ASPEK AFEKTIF SISWA DITINJAU DARI $\begin{array}{llllr}\text { KEMAMPUAN SPASIAL } & \text { SISWA. JURNAL } & \text { TATSQIF, } & 14(2) .\end{array}$ from http://ejurnal.iainmataram.ac.id/index.php/tatsqif/article/view/1008

pembelajaran kooperatif tipe Jigsaw dipilih karena dianggap bisa dipakai untuk mengajarkan materi tersebut. Topik tersebut dapat dibagai atas empat subpokok yang independen, artinya masing-masing subpokok bahasan tidak merupakan prasyarat bagi yang lain (syarat model pembelajaran kooperatif tipe Jigsaw). Dengan demikian, diharapkan melalui model pembelajaran kooperatif tipe Jigsaw pembelajaran menjadi lebih bermakna, sehingga lebih meningkatkan pemahaman siswa.

Hasil penelitian Wahyuni (2012) menunjukkan bahwa prestasi siswa meningkat pada materi pokok bangun ruang sisi datar menggunakan model pembelajaran kooperatif tipe Jigsaw dengan pendekatan matematika berjenjang. Selanjutnya, hasil penelitian yang dilakukan oleh Umami (2013) dengan menggunakan model pembelajaran kooperatif tipe Jigsaw dengan pendekatan kontekstual pada bangun ruang sisi lengkung, menunjukkan bahwa prestasi belajar meningkat, serta ekperimentasi yang dilakukan oleh Handayani (2013) dimana prestasi dengan model pembelajaran tipe Jigsaw dengan pendekatan kontekstual memberikan hasil yang lebih baik. Dua di antara penelitian tersebut menunjukkan bahwa model pembelajaran tipe Jigsaw dapat digunakan dalam materi geometri bangun ruang sisi datar ataupun bangun ruang sisi lengkung, dan keefektifan dalam memodifikasi model pembelajaran tipe Jigsaw dengan pendekatan kontekstual. Oleh karena itu, peneliti mencoba menerapkan model pembelajaran tipe Jigsaw dengan pendekatan kontektsual.

Selain pemilihan pendekatan dan model pembelajaran yang tepat, salah satu aspek yang perlu diketahui guru adalah kecerdasan yang ada dalam diri setiap siswa yang bermacam-macam. Salah satunya adalah kemampuan atau kecerdasan spasial siswa. Kemampuan spasial adalah kemampuan untuk membentuk suatu gambaran tentang tata ruang di dalam pikiran. Anak-anak dengan kecerdasan visual-spasial yang tinggi cenderung berpikir secara visual. Mereka kaya khayalan internal (internal imagery) sehingga cenderung imajinatif dan kreatif. Mengetahui dan memperhatikan kemampuan spasial 
Perwiranegara, H., K, T., \& Sujadi, I. (2016). EKSPERIMENTASI MODEL PEMBELAJARAN KOOPERATIF TIPE JIGSAW DENGAN PENDEKATAN CTL TERHADAP PRESTASI BELAJAR DAN ASPEK AFEKTIF SISWA DITINJAU DARI $\begin{array}{llllr}\text { KEMAMPUAN SPASIAL } & \text { SISWA. JURNAL } & \text { TATSQIF, } & 14(2) .\end{array}$ from http://ejurnal.iainmataram.ac.id/index.php/tatsqif/article/view/1008

siswa sangatlah penting dalam proses belajar khususnya pada matematika. Ini sesuai dengan penelitian yang dilakukan oleh Piaget (dalam Tambunan, 2006: 28) yang menyatakan bahwa kemampuan spasial merupakan salah satu aspek dari kognisi. Hasil penelitian ini menyatakan bahwa pemahaman pengetahuan spasial dapat mempengaruhi kinerja yang berhubungan dengan tugas-tugas akademik terutama matematika, membaca dan IPA. Lebih lanjut, studi yang dilakukan oleh Guay, McDaniel dan Bishop (dalam Tambunan, 2006) menemukan bahwa kemampuan spasial mempunyai hubungan positif dengan matematika pada siswa usia sekolah. Sejalan dengan penelitian yang dilakukan oleh Guay, McDaniel dan Bishop tersebut, Harmony dan Theis (2012) juga menyatakan bahwa terdapat pengaruh yang signifikan antara kemampuan spasial terhadap hasil belajar matemtaika. Selanjutnya, hal yang sama yang diungkapkan Turgut dan Yilmaz (2012) dimana hasil penelitian yang dilakukan terdapat hubungan positif antara kemampuan spasial dan keberhasilan akademis.

Tujuan penelitian ini adalah untuk mengetahui perbedaan prestasi belajar dan aspek afektif matematika yang menggunakan model pembelajaran kooperatif tipe Jigsaw dengan pendekatan CTL, model pembelajaran kooperatif tipe Jigsaw dan model pembelajaran langsung ditinjau dari kemampuan spasial, yang dikategorikan menjadi tinggi, sedang, dan rendah.

\section{METODE PENELITIAN}

Penelitian ini dilaksanakan di SMP Negeri yang ada di Kota Madiun. Jenis penelitian yang digunakan yaitu penelitian eksperimental semu dengan variabel bebas model pembelajaran dan kemampuan spasial serta variabel terikat prestasi belajar matematika dan aspek afektif matematika siswa. Populasi penelitian ini adalah seluruh siswa kelas VIII semester genap SMP Negeri di Kota Madiun Tahun Ajaran 2013/2014. Sampel diambil menggunakan teknik stratified cluster random sampling, maka terpilih sampel 
Perwiranegara, H., K, T., \& Sujadi, I. (2016). EKSPERIMENTASI MODEL PEMBELAJARAN KOOPERATIF TIPE JIGSAW DENGAN PENDEKATAN CTL TERHADAP PRESTASI BELAJAR DAN ASPEK AFEKTIF SISWA DITINJAU DARI $\begin{array}{lllll}\text { KEMAMPUAN } & \text { SPASIAL } & \text { SISWA. JURNAL } & \text { TATSQIF, } & 14(2) .\end{array}$ from http://ejurnal.iainmataram.ac.id/index.php/tatsqif/article/view/1008

SMP Negeri 3 Madiun (kategori tinggi), SMP Negeri 7 Madiun (kategori sedang), dan SMP Negeri 10 Madiun (kategori rendah).

Metode pengumpulan data penelitian meliputi metode dokumentasi, angket dan tes. Sebelum melakukan eksperimen, dilakukan uji keseimbangan terhadap kemampuan awal siswa menggunakan Multivariate Analysis of Variance (MANOVA) satu jalur yang sebelumnya diuji terlebih dahulu dengan uji normalitas multivariat dan uji kesamaan variansi dan kovariansi. Uji hipotesis dilakukan menggunakan uji Two-Way MANOVA dengan desain faktorial $3 \times 3$. Jika hasil analisis variansi menunjukkan bahwa $H_{0}$ ditolak, Rencher (2002: 183) menganjurkan dilakukan uji lanjut yaitu uji Analysis of Variance (ANOVA). Apabila $H_{0}$ masih ditolak, dilanjutkan kembali menggunakan uji komparasi ganda menggunakan metode Scheffe' (Budiyono, 2013: 215-217).

\section{HASIL PENELITIAN DAN PEMBAHASAN}

Hasil uji prasyarat menyimpulkan bahwa semua sampel berasal dari populasi yang berdistribusi normal dan populasi mempunyai variansi dan kovariansi yang sama untuk MANOVA serta variansi yang sama untuk ANOVA. Hasil uji keseimbangan dilakukan untuk mengetahui apakah populasi ketiga kelompok pembelajaran Jigsaw dengan pendekatan CTL, Jigsaw, dan langsung mempunyai kemampuan matematika yang sama. Berdasarkan hasil uji keseimbangan, disimpulkan bahwa sampel dari populasi Jigsaw dengan pendekatan CTL, Jigsaw, dan langsung dalam keadaan seimbang.

Selanjutnya, dilakukan uji hipotesis dan hasil pengujian hipotesis disajikan pada Tabel 1. 
Perwiranegara, H., K, T., \& Sujadi, I. (2016). EKSPERIMENTASI MODEL PEMBELAJARAN KOOPERATIF TIPE JIGSAW DENGAN PENDEKATAN CTL TERHADAP PRESTASI BELAJAR DAN ASPEK AFEKTIF SISWA DITINJAU DARI $\begin{array}{lllll}\text { KEMAMPUAN } & \text { SPASIAL } & \text { SISWA. JURNAL } & \text { TATSQIF, } & 14(2) .\end{array}$ from http://ejurnal.iainmataram.ac.id/index.php/tatsqif/article/view/1008

Tabel 1

Rangkuman Uji MANOVA Dua Jalan Sel Tak Sama

\begin{tabular}{ccccc}
\hline Sumber & Matriks SSCP & $F_{\text {obs }}$ & $F_{\alpha}$ & Keputusan \\
\hline $\begin{array}{c}\text { Faktor } A \\
\text { (Model Pembelajaran) }\end{array}$ & {$\left[\begin{array}{cc}5805,617 & 5803,125 \\
5803,125 & 5836,621\end{array}\right]$} & 16,64 & 2,39 & $\begin{array}{c}H_{0 \mathrm{~A}} \\
\text { ditolak }\end{array}$ \\
$\begin{array}{c}\text { Faktor } B \\
\text { (Kemampuan Spasial) }\end{array}$ & {$\left[\begin{array}{cc}22937,263 & 6709,809 \\
6709,809 & 3415,819\end{array}\right]$} & 31,28 & 2,39 & $\begin{array}{c}H_{0 \mathrm{~B}} \\
\text { ditolak }\end{array}$ \\
$A B$ & {$\left[\begin{array}{cc}666,387 & 276,637 \\
276,637 & 780,987\end{array}\right]$} & 1,195 & 1,95 & $\begin{array}{c}H_{0 \mathrm{AB}} \\
\text { Tidak }\end{array}$ \\
$\begin{array}{c}\text { (Interaksi) } \\
\text { Residual } \\
\text { (error) } \\
\text { Total } \\
\text { (corrected) }\end{array}$ & {$\left[\begin{array}{cc}50636,18 & 3726,60 \\
3726,60 & 30109,61\end{array}\right]$} & - & - & - \\
ditolak
\end{tabular}

Hasil uji Two-Way MANOVA tersebut dengan $F_{\alpha}=2,39$, pada taraf signifikansi 5\% pada model pembelajaran, kemampuan spasial menghasilkan $F_{\text {obs }}>F_{\alpha}$, yaitu berturut-turut $F_{\text {obs }}=16,64$, dan $F_{\text {obs }}=31,28$,yang berarti kedua $H_{0}$-nya ditolak, sehingga terdapat perbedaan efek model pembelajaran dan efek kemampuan spasial terhadap prestasi belajar dan aspek afektif matematika siswa. Pada interaksi, diperoleh $F_{\text {obs }}=1,195$ dan $F_{\alpha}=1,956$ pada taraf signifikansi 5\%, maka $H_{0}$ tidak ditolak. Jadi tidak terdapat perbedaan antar model pembelajaran dan kemampuan spasial terhadap prestasi belajar dan aspek afektif, serta terdapat interaksi antara model pembelajaran dan kemampuan spasial terhadap prestasi belajar dan aspek afektif matematika siswa.

Setelah itu dilakukan uji lanjut Two-Way ANOVA, untuk melihat apakah ada perbedaan pada masing-masing variabel terikat yaitu prestasi belajar dan aspek afektif. Rangkuman uji lanjut disajikan pada Tabel 2.

Tabel 2

Rangkuman Uji Lanjut Anava Dua Jalan Sel Tak Sama

\begin{tabular}{cccccccc} 
Variabel Terikat & Sumber & JK & Dk & RK & $F_{\text {obs }}$ & $F_{\alpha}$ & Keputusan \\
\hline & Faktor A & 8572,009 & 2 & 4286,004 & 21,330 & 3,032 & $H_{0 \mathrm{~A}}$ ditolak \\
Prestasi Belajar & Faktor B & 35376,409 & 2 & 17688,20 & 88,029 & 3,032 & $H_{0 \mathrm{~B}}$ ditolak \\
Matematika Siswa & & 970,31 & 4 & 242,577 & 1,207 & 2,407 & $H_{0 \mathrm{AB}}$ tidak
\end{tabular}


Perwiranegara, H., K, T., \& Sujadi, I. (2016). EKSPERIMENTASI MODEL PEMBELAJARAN KOOPERATIF TIPE JIGSAW DENGAN PENDEKATAN CTL TERHADAP PRESTASI BELAJAR DAN ASPEK AFEKTIF SISWA DITINJAU DARI $\begin{array}{lllll}\text { KEMAMPUAN } & \text { SPASIAL } & \text { SISWA. JURNAL } & \text { TATSQIF, } & 14(2) .\end{array}$ from http://ejurnal.iainmataram.ac.id/index.php/tatsqif/article/view/1008

\begin{tabular}{ccccccccc}
\hline & & & & & & ditolak \\
& Residual & 50636,182 & 252 & 200,937 & - & - & - \\
& Total & 95554,907 & 260 & - & - & - & - \\
\hline & Faktor A & 8602,253 & 2 & 4301,126 & 35,998 & 3,032 & $H_{0 \text { A ditolak }}$ \\
& Faktor B & 5199,820 & 2 & 2599,91 & 21,760 & 3,032 & $H_{0 \mathrm{~B}}$ ditolak \\
Aspek Afektif & Interaksi & 1175,91 & 4 & 293,977 & 2,460 & 2,407 & $H_{0 \mathrm{AB}}$ ditolak \\
Matematika Siswa & Residual & 30109,609 & 252 & 119,483 & - & - & - \\
& & 45087,58 & & & & - \\
& Total & 8 & & & - & & - \\
\hline
\end{tabular}

Berdasarkan uji lanjut anava dua jalan sel tak sama pada Tabel 2 disimpulkan bahwa:

(1) terdapat perbedaan efek model pembelajaran terhadap prestasi belajar maupun aspek afektif siswa, (2) terdapat perbedaan efek kemampuan spasial terhadap prestasi belajar maupun aspek afektif siswa, (3) tidak terdapat interaksi antara model pembelajaran dan kemampuan spasial terhadap prestasi belajar tetapi, terdapat interaksi antara model pembelajaran dan kemampuan spasial terhadap aspek afektif matematika siswa. Hasil perhitungan pada Tabel 2, terlihat bahwa variabel terikat prestasi belajar terdapat satu hipotesis yang tidak ditolak dan pada variabel terikat aspek afektif matematika semua hipotesis ditolak, sehingga kembali dilakukan uji komparasi ganda untuk melihat model pembelajaran dan kemampuan spasial manakah yang lebih baik pada masing-masing variabel terikat. Adapun rangkuman rerata nilai prestasi belajar dan aspek afektif disajikan pada Tabel 3.

Tabel 3

Rerata Antar Sel dan Rerata Marginal

\begin{tabular}{|c|c|c|c|c|c|c|c|c|}
\hline \multirow{3}{*}{$\begin{array}{c}\text { Model } \\
\text { Pembelajaran }\end{array}$} & \multicolumn{6}{|c|}{ Kemampuan Spasial } & \multirow{2}{*}{\multicolumn{2}{|c|}{$\begin{array}{c}\text { Rerata } \\
\text { Marginal }\end{array}$}} \\
\hline & \multicolumn{2}{|c|}{ Tinggi } & \multicolumn{2}{|c|}{ Sedang } & \multicolumn{2}{|c|}{ Rendah } & & \\
\hline & $Y_{1}$ & $Y_{2}$ & $\mathrm{Y}_{1}$ & $\mathrm{Y}_{2}$ & $\mathrm{Y}_{1}$ & $\mathrm{Y}_{2}$ & $\mathrm{Y}_{1}$ & $\mathrm{Y}_{2}$ \\
\hline Jigsaw-CTL & 83,077 & 126,462 & 71,000 & 122,533 & 55,156 & 119,969 & 68,807 & 122,761 \\
\hline Jigsaw & 77,609 & 123,304 & 66,447 & 115,447 & 54,600 & 117,000 & 65,988 & 118,000 \\
\hline Langsung & 68,118 & 120,706 & 56,800 & 105,040 & 49,286 & 110,643 & 59,195 & 112,184 \\
\hline Rerata Marginal & 75,843 & 122,410 & 65,323 & 114,935 & 53,059 & 116,024 & & \\
\hline
\end{tabular}

Uji komparasi ganda menggunakan metode Scheffe'. Adapun rangkuman uji komparasi ganda antar baris pada masing-masing variabel 
Perwiranegara, H., K, T., \& Sujadi, I. (2016). EKSPERIMENTASI MODEL PEMBELAJARAN KOOPERATIF TIPE JIGSAW DENGAN PENDEKATAN CTL TERHADAP PRESTASI BELAJAR DAN ASPEK AFEKTIF SISWA DITINJAU DARI $\begin{array}{lllll}\text { KEMAMPUAN } & \text { SPASIAL } & \text { SISWA. JURNAL } & \text { TATSQIF, } & 14(2) .\end{array}$ from http://ejurnal.iainmataram.ac.id/index.php/tatsqif/article/view/1008

terikat, uji komparasi ganda antar kolom pada masing-masing variabel terikat disajikan pada Tabel 4 dan Tabel 5.

Tabel 4

Rangkuman Hasil Uji Komparasi Ganda Antar Baris

\begin{tabular}{ccccc}
\hline Variabel Terikat & $\boldsymbol{H}_{0}$ & $\boldsymbol{F}_{\text {obs }}$ & $\boldsymbol{F}_{\alpha}$ & Keputusan Uji \\
\hline \multirow{2}{*}{ Prestasi Belajar } & $\mu_{11}=\mu_{12} \bullet$ & 1,719 & 6,063 & $H_{0}$ tidak ditolak \\
Matematika & $\mu_{11 \bullet}=\mu_{13} \bullet$ & 20,113 & 6,063 & $H_{0}$ ditolak \\
& $\mu_{12}=\mu_{13} \bullet$ & 9,932 & 6,063 & $H_{0}$ ditolak \\
\hline Aspek Afektif & $\mu_{21}=\mu_{22} \bullet$ & 8,253 & 6,063 & $H_{0}$ ditolak \\
Matematika & $\mu_{21}=\mu_{23} \bullet$ & 40,966 & 6,063 & $H_{0}$ ditolak \\
& $\mu_{22}=\mu_{23}$ & 12,244 & 6,063 & $H_{0}$ ditolak \\
\hline
\end{tabular}

Hasil uji komparasi ganda antar baris pada variabel prestasi belajar pada Tabel 4. Untuk $\mu_{11}$ •vs $\mu_{12} \bullet, F_{\text {obs }}<F_{\alpha}$ maka $H_{0}$ tidak ditolak, sehingga disimpulkan tidak terdapat perbedaan prestasi belajar matematika model pembelajaran kooperatif tipe Jigsaw dengan pendekatan CTL dengan prestasi belajar matematika model pembelajaran kooperatif tipe Jigsaw. Ini berarti model pembelajaran kooperatif tipe Jigsaw dengan pendekatan CTL menghasilkan prestasi pelajar matematika yang sama dengan model pembelajaran kooperatif Jigsaw. Untuk $\mu_{11} \bullet v s \mu_{13}, F_{\text {obs }}>F_{\alpha}$ maka $H_{0}$ ditolak, sehingga disimpulkan terdapat perbedaan prestasi belajar matematika model pembelajaran kooperatif tipe Jigsaw dengan pendekatan CTL dengan prestasi belajar matematika model pembelajaran langsung. Ini berarti model pembelajaran kooperatif tipe Jigsaw dengan pendekatan CTL menghasilkan prestasi pelajar matematika $(68,807)$ yang lebih baik daripada model pembelajaran langsung $(59,195)$, dilihat dari rerata marginalnya. Untuk $\mu_{12}$. $v s \mu_{13} \cdot, F_{\text {obs }}>F_{\alpha}$ maka $H_{0}$ ditolak, sehingga disimpulkan terdapat perbedaan prestasi belajar matematika model pembelajaran kooperatif tipe Jigsaw dengan prestasi belajar matematika model pembelajaran langsung. Ini berarti model pembelajaran kooperatif tipe Jigsaw menghasilkan prestasi pelajar matematika $(65,988)$ yang lebih baik daripada model pembelajaran langsung $(59,195)$, dilihat dari rerata marginalnya.

Hasil prestasi belajar matematika model pembelajaran kooperatif tipe Jigsaw dengan pendekatan CTL yang tidak berbeda dengan prestasi belajar 
Perwiranegara, H., K, T., \& Sujadi, I. (2016). EKSPERIMENTASI MODEL PEMBELAJARAN KOOPERATIF TIPE JIGSAW DENGAN PENDEKATAN CTL TERHADAP PRESTASI BELAJAR DAN ASPEK AFEKTIF SISWA DITINJAU DARI $\begin{array}{llllr}\text { KEMAMPUAN SPASIAL } & \text { SISWA. JURNAL } & \text { TATSQIF, } & 14(2) .\end{array}$ from http://ejurnal.iainmataram.ac.id/index.php/tatsqif/article/view/1008

matematika model pembelajaran kooperatif tipe Jigsaw, dimungkinkan karena penerapan metode kooperatif yang sama yaitu model koopertif tipe Jigsaw, serta kemungkinan juga disebabkan oleh keterbatasan peneliti dalam pelaksanaa pendekatan CTL dalam proses belajar mengajar, misalnya perangkat pembelajaran yang masih kurang sesuai menggambarkan permasalahan yang kontekstual. Walaupun dalam prakteknya, peneliti sudah maksimal dalam melaksanakan pendekatan CTL, membuat alat peraga bangun ruang untuk setiap kelompok sehingga semua siswa tidak perlu bergantian dalam memahami bangun ruang, LKS terbimbing dimana soalsoalnya di arahkan dalam kehidupan siswa, ini sejalan dengan penelitian Hammes (dalam Wasis, 2006: 4) yang menyatakan bahwa salah satu penyebap ketak berhasilnya implementasi suatu pendekatan pembelajaran adalah keterbatasan buku serta perengkat pembelajaran lain yang memberikan kemudahan bagi guru untuk menerapkan pendekatan tersebut. Perbedaan yang signifikan antar model pembelajaran kooperatif tipe Jigsaw dengan pendekatan CTL dengan model pembelajaran langsung, sesuai dengan penelitian Rosa Rosdiana Retno Handayani (2013) dimana hasil penelitiannya bahwa model pembelajaran kooperatif tipe Jigsaw dengan pendekatan kontekstual memberikan prestasi yang lebih baik dibandingkan dengan model pembelajaran NHT maupun konvensional, sedangkan perbedaan yang signifikan antar model pembelajaran kooperatif tipe Jigsaw dengan model pembelajaran langsung, sesuai dengan penelitian Arie Wahyuni (2012) dimana prestasi belajar dengan menggunakan model kooperatif tipe Jigsaw lebih baik dari pada model pembelajaran langsung.

Uji komparasi ganda antar baris pada variabel aspek afektif tersebut, untuk $\mu_{21} \cdot v s \mu_{22} . F_{\text {obs }}>F_{\alpha}$ maka $H_{0}$ ditolak, sehingga disimpulkan terdapat perbedaan aspek afektif matematika model pembelajaran kooperatif tipe Jigsaw dengan pendekatan CTL dengan aspek afektif belajar matematika model pembelajaran kooperatif tipe Jigsaw. Ini berarti model pembelajaran kooperatif tipe Jigsaw dengan pendekatan CTL $(122,761)$ menghasilkan 
Perwiranegara, H., K, T., \& Sujadi, I. (2016). EKSPERIMENTASI MODEL PEMBELAJARAN KOOPERATIF TIPE JIGSAW DENGAN PENDEKATAN CTL TERHADAP PRESTASI BELAJAR DAN ASPEK AFEKTIF SISWA DITINJAU DARI $\begin{array}{llllr}\text { KEMAMPUAN } & \text { SPASIAL } & \text { SISWA. JURNAL } & \text { TATSQIF, } & 14(2) .\end{array}$ from http://ejurnal.iainmataram.ac.id/index.php/tatsqif/article/view/1008

aspek afektif matematika yang lebih baik daripada model pembelajaran kooperatif tipe Jigsaw $(118,000)$, dilihat dari rerata marginalnya. Untuk $\mu_{21}$ • $v s \mu_{23} ., F_{\text {obs }}>F_{\alpha}$ maka $H_{0}$ ditolak sehingga disimpulkan terdapat perbedaan aspek afektif matematika model pembelajaran kooperatif tipe Jigsaw dengan pendekatan CTL dengan aspek afektif matematika model pembelajaran langsung. Ini berarti model pembelajaran kooperatif tipe Jigsaw dengan pendekatan CTL $(122,761)$ menghasilkan aspek afektif matematika yang lebih baik daripada model pembelajaran langsung $(112,184)$, dilihat dari rerata marginalnya. Untuk $\mu_{22} \bullet v s \mu_{23} . F_{\text {obs }}>F_{\alpha}$ maka $H_{0}$ ditolak, sehingga disimpulkan terdapat perbedaan aspek afektif matematika model pembelajaran kooperatif tipe Jigsaw dengan aspek afektif belajar matematika model pembelajaran langsung. Ini berarti model pembelajaran kooperatif tipe Jigsaw $(118,000)$ menghasilkan aspek afektif matematika yang lebih baik daripada model pembelajaran langsung $(112,184)$ dilihat dari rerata marginalnya.

Tabel 5.

Rangkuman Hasil Uji Komparasi Ganda Antar Kolom

\begin{tabular}{ccccc}
\hline Variabel Terikat & $H_{0}$ & $F_{\text {obs }}$ & $F_{(0,05 ; 2,252)}$ & Keputusan Uji \\
\hline Prestasi Belajar & $\mu_{1 \bullet 1}=\mu_{1 \bullet 2}$ & 23,959 & 6,063 & $H_{0}$ ditolak \\
Matematika & $\mu_{1 \bullet 1}=\mu_{1 \bullet 3}$ & 113,028 & 6,063 & $H_{0}$ ditolak \\
& $\mu_{1 \bullet 2}=\mu_{1 \bullet 3}$ & 32,371 & 6,063 & $H_{0}$ ditolak \\
\hline Aspek Afektif & $\mu_{2 \bullet 1}=\mu_{2 \bullet 2}$ & 20,335 & 6,063 & $H_{0}$ ditolak \\
Matematika & $\mu_{2 \bullet 1}=\mu_{2 \bullet 3}$ & 14,932 & 6,063 & $H_{0}$ ditolak \\
& $\mu_{2 \bullet 2}=\mu_{2 \bullet 3}$ & 0,429 & 6,063 & $H_{0}$ tidak ditolak \\
\hline
\end{tabular}

Uji komparasi ganda antar kolom pada variabel prestasi belajar di atas, untuk $\mu_{1 \bullet 1} v s \mu_{1 \bullet 2} F_{\text {obs }}>F_{\alpha}$, maka $H_{0}$ ditolak, sehingga disimpulkan terdapat perbedaan prestasi belajar matematika siswa yang berkemampuan spasial tinggi dengan prestasi belajar matematika siswa yang berkemampuan spasial sedang. Ini berarti siswa dengan kemampuan spasial tinggi $(75,843)$ mempunyai prestasi yang lebih baik dari pada siswa dengan kemampuan spasial sedang $(65,323)$, dilihat dari rerata marginalnya. Untuk $\mu_{1 \bullet 1} v s \mu_{1 \bullet 3}$ $F_{\text {obs }}>F_{\alpha}$ maka $H_{0}$ ditolak, sehingga disimpulkan perbedaan prestasi belajar 
Perwiranegara, H., K, T., \& Sujadi, I. (2016). EKSPERIMENTASI MODEL PEMBELAJARAN KOOPERATIF TIPE JIGSAW DENGAN PENDEKATAN CTL TERHADAP PRESTASI BELAJAR DAN ASPEK AFEKTIF SISWA DITINJAU DARI $\begin{array}{llllr}\text { KEMAMPUAN SPASIAL } & \text { SISWA. JURNAL } & \text { TATSQIF, } & 14(2) .\end{array}$ from http://ejurnal.iainmataram.ac.id/index.php/tatsqif/article/view/1008

matematika siswa yang berkemampuan spasial tinggi dengan prestasi belajar matematika siswa yang berkemampuan spasial rendah. Ini berarti siswa dengan kemampuan spasial tinggi $(75,843)$ mempunyai prestasi belajar yang lebih baik daripada siswa dengan kemampuan spasial rendah $(53,059)$, dilihat dari rerata marginalnya. Untuk $\mu_{1 \bullet 2} v s \mu_{1 \bullet 3} F_{\text {obs }}>F_{\alpha}$ maka $H_{0}$ ditolak, sehingga disimpulkan perbedaan prestasi belajar matematika siswa yang berkemampuan spasial sedang dengan prestasi belajar matematika siswa yang berkemampuan spasial rendah. Ini berarti siswa dengan kemampuan spasial sedang $(65,323)$ mempunyai prestasi belajar yang lebih baik daripada siswa dengan kemampuan spasial rendah $(53,059)$, dilihat dari rerata marginalnya.

Perbedaan prestasi belajar antara siswa yang berkemampuan spasial tinggi dan sedang dikarenakan siswa dengan kemampuan spasial tinggi mempunyai tingkat pemahaman yang tinggi terhadap sifat keruangan. Seseorang yang mempunyai kemampuan ini dapat menggambar di dalam pikirannya serta menuangkannya secara visual di atas kertas, sehingga masalah visualisasi geometri bukanlah masalah yang berarti. Perbedaan prestasi belajar antara siswa yang berkemampuan spasial tinggi dan rendah sesuai dengan hasil penelitian yang dilakukan Guay dan McDaniel (1977) menunjukkan siswa yang mempunyai prestasi matematika tinggi menghasilkan kemampuan spasial yang lebih baik dibandingkan dengan siswa yang mempunyai prestasi matemtika rendah. Perbedaan prestasi belajar antara siswa yang berkemampuan sedang dan rendah sesuai dengan hasil penelitian Unal, et al (2009), dimana hasil penelitiannya menunjukkan bahwa siswa dengan berkemampuan spasial tinggi dan sedang mampu mengalami peningkatan yang lebih besar dalam pemahaman geometri menurut teori Van Hiele daripada siswa dengan kemampuan spasial rendah.

Uji komparasi ganda antar kolom pada variabel aspek afektif tersebut, untuk $\mu_{2 \bullet 1} v s \mu_{2 \bullet 2}, F_{\text {obs }}>F_{\alpha}$ maka $H_{0}$ ditolak, sehingga disimpulkan terdapat perbedaan aspek afektif matematika siswa yang berkemampuan spasial 
Perwiranegara, H., K, T., \& Sujadi, I. (2016). EKSPERIMENTASI MODEL PEMBELAJARAN KOOPERATIF TIPE JIGSAW DENGAN PENDEKATAN CTL TERHADAP PRESTASI BELAJAR DAN ASPEK AFEKTIF SISWA DITINJAU DARI $\begin{array}{llllr}\text { KEMAMPUAN } & \text { SPASIAL } & \text { SISWA. JURNAL } & \text { TATSQIF, } & 14(2) .\end{array}$ from http://ejurnal.iainmataram.ac.id/index.php/tatsqif/article/view/1008

tinggi dengan aspek afektif matematika siswa yang berkemampuan spasial sedang. Ini berarti siswa dengan kemampuan spasial tinggi $(122,410)$ mempunyai aspek afektif yang lebih baik daripada siswa dengan kemampuan spasial sedang $(114,935)$, dilihat dari rerata marginalnya. Untuk $\mu_{2 \bullet 1} v s \mu_{2 \bullet 3}$ $F_{\text {obs }}>F_{\alpha}$ maka $H_{0}$ ditolak, sehingga disimpulkan perbedaan aspek afektif matematika siswa yang berkemampuan spasial tinggi dengan aspek afektif matematika siswa yang berkemampuan spasial rendah. Ini berarti siswa dengan kemampuan spasial tinggi $(122,410)$ mempunyai aspek afektif yang lebih baik daripada siswa dengan kemampuan spasial rendah $(116,024)$ dilihat dari rerata marginalnya. Untuk $\mu_{2 \bullet 2} v s \mu_{2 \bullet 3} F_{\text {obs }}<F_{\alpha}$ maka $H_{0}$ tidak ditolak, sehingga disimpulkan tidak perbedaan aspek afektif matematika siswa yang berkemampuan spasial sedang dengan aspek afektif matematika siswa yang berkemampuan spasial rendah. Ini berarti siswa dengan kemampuan spasial sedang mempunyai aspek afektif yang sama dengan siswa dengan kemampuan spasial rendah.

Untuk analisis variansi dua jalan pada variabel terikat prestasi belajar, diperoleh $H_{0 A B}$ diterima sehingga tidak perlu dilakukan uji lanjut pasca analisis variansi dengan metode Scheffe'. Jadi untuk kesimpulan hipotesis antar baris dan antar kolom pada variabel terikat prestasi belajar adalah pada masing-masing model pembelajaran, antara siswa dengan kemampuan spasial tinggi mempunyai prestasi belajar yang lebih baik dibandingkan dengan siswa dengan kemampuan spasial sedang dan rendah, dan siswa dengan kemampuan spasial sedang mempunyai prestasi belajar yang lebih baik dibandingkan dengan siswa yang mempunyai kemampuan spasial rendah. Pada masing-masing kemampuan spasial, bahwa model pembelajaran kooperatif tipe Jigsaw dengan pendekatan CTL menghasilkan prestasi belajar yang sama baiknya dengan model pembelajaran kooperatif tipe Jigsaw, akan tetapi model pembelajaran kooperatif tipe Jigsaw dengan pendekatan CTL dan model pembelajaran kooperatif tipe Jigsaw 
Perwiranegara, H., K, T., \& Sujadi, I. (2016). EKSPERIMENTASI MODEL PEMBELAJARAN KOOPERATIF TIPE JIGSAW DENGAN PENDEKATAN CTL TERHADAP PRESTASI BELAJAR DAN ASPEK AFEKTIF SISWA DITINJAU DARI $\begin{array}{llllr}\text { KEMAMPUAN } & \text { SPASIAL } & \text { SISWA. JURNAL } & \text { TATSQIF, } & 14(2) .\end{array}$ from http://ejurnal.iainmataram.ac.id/index.php/tatsqif/article/view/1008

menghasilkan prestasi belajar matematika yang lebih baik daripada model pembelajaran langsung.

Untuk analisis variansi dua jalan pada variabel terikat aspek afektif, diperoleh $H_{0 \mathrm{AB}}$ ditolak sehingga perlu dilakukan uji lanjut pasca analisis variansi dengan metode Scheffe'. Adapun rangkuman hasil uji komparasi ganda antar sel pada baris yang sama dan kolom yang sama disajikan pada Tabel 6 dan Tabel 7.

Tabel 6

Rangkuman Hasil Uji Komparasi Ganda Antar Sel Pada Baris yang Sama

\begin{tabular}{ccccc}
\hline No & $H_{0}$ & $F_{\text {obs }}$ & $F_{\text {tabel }}$ & Kesimpulan \\
\hline 1. & $\mu_{11}=\mu_{12}$ & 1,799 & 15,802 & $H_{0}$ tidak ditolak \\
2. & $\mu_{11}=\mu_{13}$ & 5,061 & 15,802 & $H_{0}$ tidak ditolak \\
3. & $\mu_{12}=\mu_{13}$ & 0,852 & 15,802 & $H_{0}$ tidak ditolak \\
4. & $\mu_{21}=\mu_{22}$ & 7,403 & 15,802 & $H_{0}$ tidak ditolak \\
5. & $\mu_{21}=\mu_{23}$ & 3,985 & 15,802 & $H_{0}$ tidak ditolak \\
6. & $\mu_{22}=\mu_{23}$ & 0,304 & 15,802 & $H_{0}$ tidak ditolak \\
7. & $\mu_{31}=\mu_{32}$ & 22,518 & 15,802 & $H_{0}$ ditolak \\
8. & $\mu_{31}=\mu_{33}$ & 8,355 & 15,802 & $H_{0}$ tidak ditolak \\
9. & $\mu_{32}=\mu_{33}$ & 3,470 & 15,802 & $H_{0}$ tidak ditolak \\
\hline
\end{tabular}

Hasil sajian Tabel 6 disimpulkan, bahwa pada model pembelajaran kooperatif tipe Jigsaw dengan pendekatan CTL dan Jigsaw, baik siswa dengan kemampuan spasial tinggi, sedang dan rendah mempunyai aspek afektif yang sama. Hal ini dimungkinkan karena penerapan model kooperatif yang sama yaitu model koopertif tipe Jigsaw, serta kemungkinan juga disebabkan oleh keterbatasan peneliti dalam pelaksanaan pendekatan CTL dalam proses belajar mengajar, misalnya perangkat pembelajaran yang masih kurang sesuai menggambarkan permasalahan yang kontekstual. Pada model pembelajaran langsung, siswa dengan kemampuan spasial tinggi mempunyai aspek afektif yang lebih baik dibandingkan dengan siswa yang mempunyai kemampuan spasial sedang, sedangkan siswa dengan kemampuan spasial tinggi dan rendah maupun siswa dengan kemampuan spasial sedang dan rendah mempunyai aspek afektif yang sama baiknya. Hal ini dimungkinkan dari model pembelajaran langsung yang digunakan dalam mengajarkan materi 
Perwiranegara, H., K, T., \& Sujadi, I. (2016). EKSPERIMENTASI MODEL PEMBELAJARAN KOOPERATIF TIPE JIGSAW DENGAN PENDEKATAN CTL TERHADAP PRESTASI BELAJAR DAN ASPEK AFEKTIF SISWA DITINJAU DARI $\begin{array}{lllll}\text { KEMAMPUAN } & \text { SPASIAL } & \text { SISWA. JURNAL } & \text { TATSQIF, } & 14(2) .\end{array}$ from http://ejurnal.iainmataram.ac.id/index.php/tatsqif/article/view/1008

ini kurang bermakna. Dalam proses pengajaran tidak memberikan ruang yang luas untuk siswa dapat memahami secara mendalam dan membangun pengetahuannya sendiri. Ini dikarenkan, siswa hanya diberi materi dan penguatan secara lisan mengenai penggunaannya dan latihan-latihan soal yang berakibat tidak meratanya perkembangan afektif matematika siswa.

Tabel 7

Rangkuman Hasil Uji Komparasi Ganda Antar Sel Pada Kolom yang Sama

\begin{tabular}{ccccc}
\hline No & $H_{0}$ & $F_{\text {obs }}$ & $F_{\text {tabel }}$ & Kesimpulan \\
\hline 1. & $\mu_{11}=\mu_{21}$ & 1.018 & 15.802 & $H_{0}$ tidak ditolak \\
2. & $\mu_{11}=\mu_{31}$ & 7.417 & 15.802 & $H_{0}$ tidak ditolak \\
3. & $\mu_{21}=\mu_{31}$ & 2.428 & 15.802 & $H_{0}$ tidak ditolak \\
4. & $\mu_{12}=\mu_{22}$ & 7.045 & 15.802 & $H_{0}$ tidak ditolak \\
5. & $\mu_{12}=\mu_{32}$ & 34.925 & 15.802 & $H_{0}$ ditolak \\
6. & $\mu_{22}=\mu_{32}$ & 13.670 & 15.802 & $H_{0}$ tidak ditolak \\
7. & $\mu_{13}=\mu_{23}$ & 1.035 & 15.802 & $H_{0}$ tidak ditolak \\
8. & $\mu_{13}=\mu_{33}$ & 10.870 & 15.802 & $H_{0}$ tidak ditolak \\
9. & $\mu_{23}=\mu_{33}$ & 4.467 & 15.802 & $H_{0}$ tidak ditolak \\
\hline
\end{tabular}

Hasil sajian Tabel 7 disimpulkan, bahwa pada siswa dengan kemampuan spasial tinggi dan rendah, baik model pembelajaran kooperatif tipe Jigsaw dengan pendekatan CTL, Jigsaw maupun model pembelajaran langsung, menghasilkan aspek afektif yang sama baiknya. Hal ini dimungkinkan dari model pembelajaran yang digunakan, dimana masingmasing model pembelajaran dapat meningkatkan aspek afektif untuk siswa dengan kemampuan spasial rendah, sehingga siswa dengan kemampuan spasial rendah mempunyai aspek afektif yang sama dengan siswa yang mempunyai kemampuan spasial tinggi. Pada siswa dengan kemampuan spasial sedang, model pembelajaran kooperatif tipe Jigsaw dengan pendekatan CTL menghasilkan aspek afektif yang lebih baik dibandingkan dengan siswa yang diberi model pembelajaran langsung, sedangkan model pembelajaran kooperatif tipe Jigsaw dengan pendekatan CTL dan model pembelajaran kooperatif tipe Jigsaw maupun model pembelajaran kooperatif tipe Jigsaw dan model pembelajaran langsung menghasilkan aspek afektif yang sama baiknya. Perbedaan aspek afektif model pembelajaran kooperatif 
Perwiranegara, H., K, T., \& Sujadi, I. (2016). EKSPERIMENTASI MODEL PEMBELAJARAN KOOPERATIF TIPE JIGSAW DENGAN PENDEKATAN CTL TERHADAP PRESTASI BELAJAR DAN ASPEK AFEKTIF SISWA DITINJAU DARI $\begin{array}{llllr}\text { KEMAMPUAN SPASIAL } & \text { SISWA. JURNAL } & \text { TATSQIF, } & 14(2) .\end{array}$ from http://ejurnal.iainmataram.ac.id/index.php/tatsqif/article/view/1008

tipe Jigsaw dengan pendekatan CTL dan model pembelajaran langsung dikarenakan karakteristik dari model pembelajaran kooperatif tipe Jigsaw dengan pendekatan CTL yang dapat meningkatkan aspek afektif pada siswa dengan kemampuan spasial rendah, sedangkan hasil aspek afektif yang sama dari ketiga model untuk siswa dengan kemampuan sedang dimungkinkan model pembelajaran kooperatif yang digunakan kurang maksimal dijalankan dan dikarenakan siswa yang belum terbiasa dengan pembelajaran kelompok.

\section{SIMPULAN DAN SARAN}

Berdasarkan hasil analisis data menggunakan MANOVA dan ANAVA, diperoleh kesimpulan sebagai berikut. (1) Model pembelajaran kooperatif tipe Jigsaw dengan pendekatan CTL dan model pembelajaran kooperatif tipe Jigsaw menghasilkan prestasi belajar yang lebih baik daripada model pembelajaran langsung, sedangkan model pembelajaran kooperatif tipe Jigsaw dengan pendekatan CTL menghasilkan prestasi belajar yang sama baiknya dengan model pembelajaran kooperatif tipe Jigsaw. (2) Model pembelajaran kooperatif tipe Jigsaw dengan pendekatan CTL menghasilkan aspek afektif yang lebih baik daripada model pembelajaran kooperatif tipe Jigsaw dan model pembelajaran langsung, serta model pembelajaran kooperatif tipe Jigsaw menghasilkan aspek afektif yang lebih baik daripada model pembelajaran langsung. (3) Siswa dengan kemampuan spasial tinggi dan sedang mempunyai prestasi belajar yang lebih baik daripada siswa dengan kemampuan spasial rendah, serta siswa dengan kemampuan spasial sedang mempunyai prestasi belajar yang lebih baik daripada siswa dengan kemampuan spasial rendah. (4) Siswa dengan kemampuan spasial tinggi mempunyai aspek afektif yang lebih baik daripada siswa dengan kemampuan spasial sedang dan rendah, serta aspek afektif siswa dengan kemampuan spasial sedang sama baiknya dengan siswa yang mempunyai kemampuan sapasial rendah. (5) Pada model pembelajaran kooperatif tipe Jigsaw dengan pendekatan CTL, Jigsaw dan langsung, prestasi belajar siswa dengan kemampuan spasial tinggi lebih baik dibandingkan dengan siswa yang 
Perwiranegara, H., K, T., \& Sujadi, I. (2016). EKSPERIMENTASI MODEL PEMBELAJARAN KOOPERATIF TIPE JIGSAW DENGAN PENDEKATAN CTL TERHADAP PRESTASI BELAJAR DAN ASPEK AFEKTIF SISWA DITINJAU DARI $\begin{array}{llllr}\text { KEMAMPUAN SPASIAL } & \text { SISWA. JURNAL } & \text { TATSQIF, } & 14(2) .\end{array}$ from http://ejurnal.iainmataram.ac.id/index.php/tatsqif/article/view/1008

mempunyai kemampuan spasial sedang dan rendah, serta prestasi belajar siswa dengan kemampuan spasial sedang lebih baik dibandingkan dengan siswa yang mempunyai kemampuan spasial rendah. (6) Pada model pembelajaran kooperatif tipe Jigsaw dengan pendekatan CTL dan Jigsaw, baik siswa dengan kemampuan spasial tinggi, sedang dan rendah mempunyai aspek afektif yang sama. Pada model pembelajaran langsung, siswa dengan kemampuan spasial tinggi mempunyai aspek afektif yang lebih baik dibandingkan dengan siswa yang mempunyai kemampuan spasial sedang, sedangkan siswa dengan kemampuan spasial tinggi dan rendah maupun siswa dengan kemampuan spasial sedang dan rendah mempunyai aspek afektif yang sama baiknya. (7) Pada kategori kemampuan spasial tinggi, sedang dan rendah, prestasi belajar siswa pada model pembelajaran kooperatif tipe Jigsaw dengan pendekatan CTL dan Jigsaw lebih baik dibandingkan pada model pembelajaran langsung, serta prestasi belajar siswa pada model pembelajaran kooperatif tipe Jigsaw dengan pendakatan CTL dan model pembelajaran kooperatif tipe Jigsaw sama baiknya. (8) Pada siswa dengan kemampuan spasial tinggi dan rendah, baik model pembelajaran kooperatif tipe Jigsaw dengan pendekatan CTL, Jigsaw maupun model pembelajaran langsung, menghasilkan aspek afektif yang sama baiknya. Pada siswa dengan kemampuan spasial sedang, model pembelajaran kooperatif tipe Jigsaw dengan pendekatan CTL menghasilkan aspek afektif yang lebih baik dibandingkan dengan siswa yang diberi model pembelajaran langsung, sedangkan model pembelajaran kooperatif tipe Jigsaw dengan pendekatan CTL dan model pembelajaran kooperatif tipe Jigsaw maupun model pembelajaran kooperatif tipe Jigsaw dan model pembelajaran langsung menghasilkan aspek afektif yang sama baiknya.

Sesuai simpulan dari penelitian ini, peneliti memberikan saran sebagai berikut. (1) Bagi guru, guru hendaknya dapat memilih model pembelajaran yang tepat untuk meningkatkan prestasi belajar dan aspek afektif siswa, khususnya pada materi bangun ruang. Salah satu model 
Perwiranegara, H., K, T., \& Sujadi, I. (2016). EKSPERIMENTASI MODEL PEMBELAJARAN KOOPERATIF TIPE JIGSAW DENGAN PENDEKATAN CTL TERHADAP PRESTASI BELAJAR DAN ASPEK AFEKTIF SISWA DITINJAU DARI $\begin{array}{llllr}\text { KEMAMPUAN } & \text { SPASIAL } & \text { SISWA. JURNAL } & \text { TATSQIF, } & 14(2) .\end{array}$ from http://ejurnal.iainmataram.ac.id/index.php/tatsqif/article/view/1008

pembelajaran yang dapat meningkatkan prestasi belajar dan aspek afektif siswa adalah model pembelajaran kooperatif Jigsaw dengan pendekatan CTL. Secara praktis dalam proses pelaksanaannya kedua model ini, model pembelajaran kooperatif tipe Jigsaw lebih mudah untuk diterapkan. Kemampuan mengembangkan model pembelajaran di sekolah sangat diperlukan dilakukan oleh guru, hal ini sebagai langkah terbaik untuk mengatasi kebosanan yang dialami siswa dalam belajar. Persiapan yang matang sebelum proses pembelajaran juga diperlukan, baik dari persiapan media yang akan digunakan, persiapan diri dalam melaksanakan langkahlangkah pembelajaran maupun waktu yang digunakan agar pembelajaran berjalan dengan lancar dan menyenangkan. Model pembelajaran yang diterapkan oleh guru juga diharapkan mampu memberikan perlakuan yang sama sesuai dengan karakteristik siswa, misalnya kemampuan spasial yang dimiliki oleh siswa. (2) Peneliti selanjutnya, hendaknya dapat melakukan penelitian dengan kajian yang lebih mendalam lagi tentang model pembelajaran kooperatif tipe Jigsaw dengan pendekatan CTL, tentang pembuatan perangkat pembelajaran yang tepat dengan pendekatan CTL. Peneliti lanjutan juga hendaknya dapat melakukan penelitian dengan model pembelajaran lainnya yang sekiranya sesuai dengan tipe kemampuan spasial yang dimiliki siswa.

\section{DAFTAR PUSTAKA}

Abdussakir dan Nur Laili Achadiyah. 2009. Pembelajaran Keliling dan Luas Lingkaran dengan Strategi React Pada Siswa Kelas VIII SMP Negeri Kota Mojokerto. Prosiding dalam Seminar Nasional Matematika dan Pendidikan Matematika FMIPA UNY, ISBN :978-979-16352-3-2, pp 388-401.

Arie Wahyuni. 2012. Eksperimentasi Model pembelajaran kooperatif tipe Jigsaw dengan Pendekatan Matematika Berjenjang Ditinjau dari Minat Belajar Siswa SMP Negeri Kota Semarang. Tesis. Surakarta: Universitas Sebelas Maret.

Budiyono. 2013. Statistika Untuk Penelitian Edisi Ke-2. Surakarta: UNS Press. 
Perwiranegara, H., K, T., \& Sujadi, I. (2016). EKSPERIMENTASI MODEL PEMBELAJARAN KOOPERATIF TIPE JIGSAW DENGAN PENDEKATAN CTL TERHADAP PRESTASI BELAJAR DAN ASPEK AFEKTIF SISWA DITINJAU DARI $\begin{array}{llllr}\text { KEMAMPUAN } & \text { SPASIAL } & \text { SISWA. JURNAL } & \text { TATSQIF, } & 14(2) .\end{array}$ from http://ejurnal.iainmataram.ac.id/index.php/tatsqif/article/view/1008

Berns, R. G. dan Erickson, P. M. 2001. Contextual Teaching and Learning: Preparing Students for the New Economy. The Highlight Zone Research. No. 5, pp 1-8.

Clements, D.H. dan Battista, M.T. 1992. Geometry and Spatial Reasonning. Dalam Grouws, D.A. (Ed.). Handbook of Research on Mathematics Teaching and Learning. New York: MacMillan Publisher Company, pp 420-464.

Farah Umami. 2013. Eksperimentasi Pembelajaran Kooperatif Tipe Jigsaw dengan Pendekatan Kontekstual Berbasis Lesson Study Pada Materi Bangun Ruang Sisi Lengkung Ditinjau dari Gaya Belajar Siswa Kelas IX MTs Negeri Kabupaten Madiun Tahun Pelajaran 2012/2013. Tesis. Surakarta: Universitas Sebelas Maret.

Fuys, D., Geddes, D., dan Tischer, R. 1988. The Van Hiele Model of Thinking in Geometry Among Adolescents. Journal for Research in Mathematics Education. Monograph No. 3. Reston: NCTM.

Guay, R. B. dan McDaniel, E. D. 1977. The Relation Between Mathematics Achievement and Spasial Abilities Among Elementary School Chidren. Journal of Research in Mathematics Education. Vol. 8. No. 3, pp 163-240.

Harmony, J. dan Theis, R. 2012. Pengaruh Kemampuan Spasial terhadap Hasil Belajar Matematika Siswa Kelas VII SMP Negeri 9 Kota Jambi. Edumatica. Vol. 2. No. 1, pp 11-19.

Kokom Komalasari. 2010. Pembelajaran Kontekstual: Konsep dan Aplikasi. Refika Aditama. Bandung.

Lim, S. Y. dan Chapman, E. 2013. Identifying Affective Domains That Correlate and Predict Mathematics Performance in High-Performing Students in Singapore. Educational Psychology.

Nana Sudjana. 2008. Penilaian Hasil Proses Belajar Mengajar. Bandung: PT. Remaja Rosdakarya.

Nurty Gofita Sari. 2013. Aspek Afektif Taksonomi Bloom pada Pembelajaran Matematika Siswa Kelas VI Sekolah Dasar Se-Kecamatan Alian. Jurnal Pendidikan Matematika. ISSN 237-441. Vol. 1. No. 1, pp 20-27.

Rencher, A. C. 2002. Methods of Multivariate Analysis. Kanada: John Wiley and Sons, Inc.

Rosa Rosdiana Retno Handayani. 2013. Eksperimentasi Model Pembelajaran Numbered Heads Together dan Jigsaw dengan Pendekatan Kontekstual Terhadap Prestasi Belajar Matematika Ditinjau dari Kecerdasan 
Perwiranegara, H., K, T., \& Sujadi, I. (2016). EKSPERIMENTASI MODEL PEMBELAJARAN KOOPERATIF TIPE JIGSAW DENGAN PENDEKATAN CTL TERHADAP PRESTASI BELAJAR DAN ASPEK AFEKTIF SISWA DITINJAU DARI $\begin{array}{lllll}\text { KEMAMPUAN } & \text { SPASIAL } & \text { SISWA. JURNAL } & \text { TATSQIF, } & 14(2) .\end{array}$ from http://ejurnal.iainmataram.ac.id/index.php/tatsqif/article/view/1008

Majemuk Siswa SMP Negeri Kota Madiun. Tesis. Surakarta: Universitas Sebelas Maret.

Siti Marliah Tambunan. 2006. Hubungan Antara Kemampuan Spasial dengan Prestasi Belajar Matematika. Jurnal Makara, Sosial Humaniora. Vol. 9. No. 1, pp 27-32.

Somerset, A. 1996. Strengthening Quality in Indonesia's Junior Secondary Schools: An Overview of Issues and Initiatives. Jakarta: MOEC.

Sukanti. 2011. Penilaian Afektif Dalam Pembelajaran Akuntansi. Jurnal Pendidikan Akuntansi Indonesia. Vol. 9. No. 1, pp 74-82.

Sutama, Haryoto dan Sabar Narimo. 2013. Contextual Math Learning Based on Lesson Study Can Increase Study Communication. International Journal of Education. Vol. 5. No. 4, pp 48-60.

Turgut, M. dan S. Yilmaz. 2012. Relationship Among Preservice Primary Mathematics Teacher' Gender, Academic Success and Spatial Ability. International Journal of Instruction. Vol. 5. No. 2, pp 5-20.

Unal, H., Jakubowski, E. dan Corey, D. 2009. Differences in Learning Geometry among High and Low Spatial Ability Pre-Service Mathematics Teachers. International Journal of Mathematical Education in Science and Technology. Vol. 40. No. 8, pp 997-1012.

Wasis. 2006. Contextual Teaching and Learning (CTL) dalam Pembelajaran Sains-Fisika. Cakkrawala Pendidikan. Vol. 25. No.1, pp 388-401.

Westera, W. 2011. On the Changing Nature of Learning Context: Anticipating the Virtual Extensions of the World. Educational Technology \& Society. Vol. 14. No. 2, pp 201-212.

Zakaria, E. dan Iksan, Z. 2007. Promoting Cooperative Learning in Science and Mathematics Education: A Malaysian Perspective. Eurasia Journal of Mathematics, Science and Technology Education. Vol. 3. No. 1, pp 35-39. 